\title{
Ella's Kitchen: strategic positive leadership with purpose and value-driven collective energy
}

Book or Report Section

Accepted Version

Ahmadi, A. and Vogel, B. (2017) Ella's Kitchen: strategic positive leadership with purpose and value-driven collective energy. In: Koonce, R., Robinson, P. and Vogel, B. (eds.) Developing Leaders for Positive Organizing. Emerald, pp. 307320. ISBN 9781787142411 Available at https://centaur.reading.ac.uk/82081/

It is advisable to refer to the publisher's version if you intend to cite from the work. See Guidance on citing.

Published version at: https://www.emeraldinsight.com/doi/full/10.1108/978-1-78714-240-420171024

Publisher: Emerald

All outputs in CentAUR are protected by Intellectual Property Rights law, including copyright law. Copyright and IPR is retained by the creators or other copyright holders. Terms and conditions for use of this material are defined in the End User Agreement.

www.reading.ac.uk/centaur 
Central Archive at the University of Reading

Reading's research outputs online 


\section{Ella's Kitchen: Strategic Positive Leadership with Purpose and Value-Driven Collective Energy}

Ella's Kitchen is a UK-based baby food company that was founded in 2006 by Paul and Alison Lindley - parents of Ella, their then 6-year-old daughter - with a passion to develop healthy and organic nutrition that sustainably changes the eating habits of young children. The company revolutionized the baby food market in the UK and became an internationally recognized brand, winning awards as an innovator and as an employer. Paul Lindley and his management team created what they coined "Ella's-ness", an organizational philosophy and way of being that combines business with fun and excitement to develop and maintain a highly energized and unique climate as a backbone for an innovative and successful organization. This case explores the shared purpose, vision, mission, and values, as well as the positive collective human experience of the company, all of which were crucial drivers for positive energy and performance.

\section{Energising vision, mission and shared purpose}

The Lindley's founded Ella's Kitchen with a passion to create healthy baby food and eating habits for infants and children. Paul Lindley states, "I set up Ella's Kitchen because I passionately believe that Ella, my daughter, along with her generation, should have the opportunity to eat better food and also to discover that healthy food can be fun, tasty, and cool... Our mission is to develop healthy eating habits that last a lifetime by offering a range of tasty, natural, and healthy $100 \%$ organic foods for babies and kids".

The company maintained this mission in its work with partners, retailers, and customers. Internally, Paul Lindley translated the mission into a mobilizing goal for the people at Ella's Kitchen. For instance, the company referred to sales targets as "Tiny Tummy Touch Points", a term that made the ambition more tangible and also more exciting. The term captured the company's vision of giving each individual consumer - baby or child and parent - a unique healthy experience. Every month at the company-wide "Tea at Two" meeting, Paul recognized the achievements of employees against the mission by showing progress of the Tiny Tummy Touch Points goal by adding to a transparent tube a 
number of sealing caps equal to the sold food pouches, representing the additional sales towards the Tiny Tummy Touch Point targets. For years, this tube stood at the entrance to the company as a visible reminder to all employees and visitors about the purpose and ambition of the business. Paul defined Ella's Kitchen's brand values as being genuine, imaginative, and inspiring and wanted Ella's Kitchen to be "the same brand inside and out". Employees had a strong sense of ownership for the shared purpose and deeply meaningful goal, and enjoyed the fast-paced journey of the company, sustaining motivation, and excitement towards hitting the company's targets.

\section{Positive and lived organizational values}

Together with the vision and mission, Ella's Kitchen's values were drivers for the shared engagement of employees. In 2012, Ella's Kitchen translated its strategy and brand attributes into five internal values: (1) We're childlike, (2) We think differently, (3) We're good to each other, (4) We want to win, and (5) We're business minded. These seemingly contradicting values were aimed towards a climate of innovativeness, concern for people, but also a very ambitious and business-driven company. Ella's Kitchen created a tangible embodiment of these values with the "Values Buddy". To further implement the shared beliefs, the Values Buddy was visually present throughout the company, e.g., on mouse mats and notebooks. Furthermore, in the "Big Chat" periodic employee appraisals, employees had to identify examples of how the values came alive and were meaningful in their roles and activities. As a result, employees at Ella's Kitchen showed more consistent behaviour and a strong sense of ownership of the company's story and guiding principles.

Ella's Kitchen's philosophy also became alive in the company's distinctive language. For instance, on the product side, snack products were called puffits, yum yummy cookies, nibbly fingers and munchy biccies. Inside Ella's Kitchen, Paul and his colleagues avoided typical management jargon and found expressions that represented the ambition of roles with playfulness. The top management team was called the "Little Huddle", while the marketing team was called "Making Friends", operations 
was "Make it Run Like Clockwork", and new product development was titled "Yummy New Stuff”. Different roles within teams became "heads", "runs", "makes", and "helps" roles. For example, the Finance Director was "Head of Making the Sums Work", while a Finance Assistant was "Helps Make the Sums Work". Terms like Tea at Two, Big Chat, and Tiny Tummy Touch Points followed a similar logic. Using a specific language for roles, processes, and targets, and filling it with key business activities provide another lever to create meaning around Ella's Kitchen's principles of reflecting a playful and imaginative, yet performance-driven company.

\section{Positive collective human experience as positive energy}

Typically for a start up, the founders and employees were enthusiastic and dedicated. Yet the management team identified early that maintaining this is decisive for their business and thus initiated what they called 'Ella's-ness', a unique collective experience of feeling energetic, enthusiastic, and ambitious towards the business. The company systematically pursued activities, such as those mentioned above, to sustain this experience among employees. The management team also radiated low status difference to all employees with an informal, inviting, and welcoming style of leadership. Employees' opinions and ideas mattered, and open communication across the organization was crucial. Employees felt a great sense of belonging, and experienced an open and sociable atmosphere.

As the company expanded, the management team continued to sit among employees to keep communication and information exchange fluid and transparent. The rapid expansion of Ella's Kitchen with the need for more office space challenged the people- and climate-centred leadership. The management team put great effort into identifying solutions that catered for recruiting more people without losing the key element of their treasured climate and connections among employees. They listened carefully to employees for signs of a changing climate at Ella’s Kitchen. In 2009, Paul set up Tea at Two, a monthly meeting for all employees as a hub for activities, initiatives and communications about the business, such as the Tiny Tummy Touch Point target. Tea at Two also included a slot called 
"A Week in the life of..." where one employee reported on their role and shared their experiences, challenges, and achievements with others across the company. In 2010, Paul started, "Scores on the Doors", a weekly email updating all employees on the business. While growing in employee numbers, Paul remained visible and approachable and the company transparent to its employees as members of the "family". Moreover, in 2012, Catherine Allen, HR Director or "Head of Making People Happy", and the leadership team identified the need to have leadership quality not only at the top of the company, but to leverage management and leadership skills across the business. In addition to the tools implemented like the Big Chat, they initialized a management program that they called "The Super Buddies", which anchored around Ella's Kitchen's five core values. Over time, the program systematically developed all existing and newly joining or promoted managers to create and maintain consistent positive and likewise performance-driven leadership across the organization.

\section{SCHOLARLY COMMENTARY}

This case study focuses on learning in three areas that represent potential building blocks for positive strategic leadership (Bruch \& Vogel, 2011; Cameron, 2008) and manifest positive work environments that help organizations to thrive (Cameron \& Spreitzer, 2013).

\section{Energising vision, mission and shared purpose}

While the aim of leadership may be viewed as the neutral pursuit of results (Grint, 2005), Ella's Kitchen's philosophy and practices point to the significance of a positive (Cameron, Dutton, \& Quinn, 2003) interpretation to strategic leadership (Boal \& Hooijberg, 2000; Yukl, 2008) in terms of leading positive meaning (Cameron, 2008). Astonishingly for a young company in the competitive retail market, the founders of Ella's Kitchen withstood the tendency for start-ups to focus purely on profit, and instead identified the meaningfulness of the company and therefore the meaning of work to employees (Albrecht, 2013) as a condition of their success. 
The energy that people experience when they are purpose-driven can be influential and contagious (Quinn \& Quinn, 2015). The case study shows how the founders implemented strategic leadership practices to build the company's purpose that was shared and viewed as not only truly beneficial to people outside the business (Grant, 2012), but also effective in internally mobilizing the collective positive energy of employees. Examples are the Tiny Tummy Touch Points tangibly located at the entrance of the company, with targets regularly checked at the Tea at Two meetings.

A meaningful vision, mission, and shared purpose can become energizing and have positive impacts on individual and organizational outcomes. Hackman and Oldham (1976, p. 256) define experienced meaningfulness at work as "the degree to which the individual experiences the job as one which is generally meaningful, valuable, and worthwhile". The literature on meaningful work points to various conditions that can provide meaningfulness (e.g. Cameron, 2008; Michaelson, 2005), which are beyond the focus of the current discussion. In light of the case study, when employees feel that their work is significant (in this case making a difference to the nutrition and health of children), they may experience their tasks as meaningful and be more motivated at work (Grant, 2007). Additionally, when employees view their work as meaningful, they may feel more energized (Quinn \& Quinn, 2015) and exert more effort, engagement, and commitment to their work and organization (Cameron, 2008). Overall, Hackman and Oldham (1976) view meaningfulness as a critical psychological state that can contribute towards high motivation, high work satisfaction, low absenteeism and turnover, and high performance. The case study sheds light on the importance of considering the quality of shared and meaningful ambitions (Kempster, Jackson \& Conroy, 2011), positive organizational purpose (Bruch \& Vogel, 2011; Cameron, 2008) and the positive meaning that people attach to it (Baumeister \& Vohs, 2002).

\section{Positive and lived organizational values}


Another element of positive strategic leadership builds on values and culture as systems of positive work environments (Haertel \& Ashkanasy, 2010). Values are a powerful manifestation in the lives of individuals and an essential component of positive organizational cultures and performance (Kotter \& Heskett, 1992). The case study uncovers how the individual, relational, and collective values of Ella's Kitchen were drivers for high collective energy guiding the organization's day-to-day activities.

As defined by Rokeach (1973), value is as "an enduring belief that a specific mode of conduct or end-state of existence is personally or socially preferable" (p. 5); a value system can be defined as "an organized set of preferential standards" that can both justify past conduct and guide future behavior (Rokeach, 2008, p. 20). A positive organizational system of shared values, involving the right scope and strength of values for the specific organization (Bruch \& Vogel, 2011) and manifesting in cultural symbols (Glynn \& Watkis, 2011) can be significant in driving positive energy. Nonetheless, Cha and Edmondson (2006) suggest that a strong emphasis on shared values in organizations (what they refer to as value expansion) can be a double-edged sword. While values may play an important role in advancing meaningfulness at work, value expansion may also raise the risk of employee attributions of leader hypocrisy and employee disenchantment (Cha \& Edmondson, 2006) depending on the experiences employees and managers and the quality of leadership relationships in an organization.

Ella's Kitchen aimed to strike the right balance, emphasizing its core values visually through the "Values Buddy" but also allowing opportunities for these to be reflected upon by all members of the organization in processes like the 'Big Chat'. Employees participated in shaping the 'Values Buddy' and generally identified with the Ella's Kitchen's values, and when values and follower self-identities are coherent and interrelated, positive leadership impacts can be achieved (Lord \& Brown, 2001). Further, while in essence all of Ella's Kitchen's values have positive and generative connotations, employees might not always be able to reconcile possible frictions in applying some of the value statements, for 
instance "We're good to each other" and "We're business-minded". Making such possible paradoxical situations transparent that an organization may face can serve as a positive tension that energizes employees and organizations towards better decisions, processes, and outcomes.

\section{Positive collective human experience as positive energy}

The case study shows how the company created 'Ella's-ness' and pursued systematic activities to sustain this shared experience as the company expanded. Ella's-ness contributed to a collective experience of openness, belongingness and sense of family (Koonce, 2016) which, in turn, enhanced the positive energy in the organization. Drawing on literature on human energy that captures individual energy (e.g. Quinn \& Dutton, 2005; Quinn, Spreitzer, \& Lam, 2012), relational energy (e.g. Owens, Baker, McDaniel Sumpter, \& Cameron, 2016), collective energy (e.g. Cole, Bruch \& Vogel, 2012; Vogel \& Bruch 2011) and collective engagement (e.g. Barrick, Thurgood, Smith, \& Courtright, 2015), research shows how human energy can support positive outcomes for organizations and their members. Ella's Kitchen specifically illustrates the meaning of collective positive energy as an essential force in the pursuit of its shared goals (Bruch \& Vogel, 2011; Dutton, 2003).

Cole, Bruch, and Vogel (2012, p. 447) expand beyond the energy-as-affect perspective (e.g. Quinn \& Dutton, 2005) to capture energy in collectives as "the shared experience and demonstration of positive affect, cognitive arousal, and agentic behavior among unit members in their joint pursuit of organizationally salient objectives". Research distinguishes between different states of collective energy (Bruch \& Vogel, 2011) based on two dimensions: intensity (high-low), which refers to the strength or level of organizational energy experienced in a collective unit when it is active or alert; and the quality of organizational energy (positive-negative), that characterizes the extent to which a unit's energy is constructive or destructive regarding the shared organizational goals. This allows differentiating four types of energy states (Bruch \& Vogel, 2011, p.10): 
- Productive energy (high positive energy): Characterized by high employee emotion and mental alertness along with high activity levels, speed, and stamina.

- Comfortable energy (low positive energy): Characterized by high employee satisfaction and identification coupled with low activity levels and complacency.

- Resigned inertia (low negative energy): Characterized by high levels of employee frustration, mental withdrawal, cynicism, and low engagement.

- Corrosive energy (high negative energy): Characterized by aggression and destructive behaviour, for example through internal politics, resistance to change, and maximizing individual benefits.

In light of this case study, Ella's Kitchen showed high levels of productive energy. The leadership team focused on creating conditions that allowed employees to experience in particular collective productive energy to flourish and prosper in extraordinary ways (Spreitzer \& Sonenshein, 2004). Having led the organization into such a state, the leadership activities became more concerned with how to maintain Ella's-ness, which represents the leadership challenge of sustaining, in contrast to mobilizing, a healthy level of shared energy across an organization over time.

Positive strategic leadership (e.g. Bruch \& Vogel, 2011; Cameron, 2008) helps to create sustained human energy by working with strategy, structure and processes, culture and leadership as management systems that leadership teams can develop for their organizations. In the case of Ella's Kitchen, the emphasis on positive meaningfulness through purpose, values, and culture was supported by developing structures and processes that allowed for meaningful interpersonal interactions and relationships (Wrzesniewski, Dutton, \& Debebe, 2003), a sense of community (Grant, 2007; Podolny, Khurana, \& Hill-Popper, 2004), and a sense of belonging at work (Baumeister \& Leary, 1995). Activities like Tea at Two and A Week in the Life of... can be viewed as "small actions" with "big 
impact” for building positive leadership (Dutton \& Spreitzer, 2014), and hence foster a positive collective experience of meaningfulness for workers at Ella's Kitchen.

Meaningful interpersonal relationships can, in turn, shape positive energy in organizations. For instance, the sense of being interpersonally accepted and respected may raise positive emotions like appreciation and gratitude, as well as increase creativity (Carmeli, Dutton, \& Hardin, 2015).

Furthermore, positive exchanges between leaders and followers (Bono \& Ilies, 2006; Johnson, 2008) and among co-workers (Cole et al., 2012; Quinn \& Dutton, 2005) can fuel positive energy and become energizing at a higher level through emotional contagion (Barsade, 2002; Hatfield, Cacioppo, \& Rapson, 1994).

Finally, in addition to the positive energy transfer across the organization, research on leadership climate (Menges, Walter, Vogel, \& Bruch, 2011) suggests considering the quality of leadership at all levels of an organization. Although many of the positive leadership practices at Ella's Kitchen were initialized by the founders and the leadership team at the top of the organization, an ambition that later became a focus with systematic leadership development for all managers across the organization is the “The Super Buddies" program. A key milestone in a relatively small and new business, Ella's Kitchen believed that consistent positive and ambitious leadership across the organization, alongside the meaningful vision, purpose, and values, would help sustain Ella's-ness and overall success.

\section{Discussion Questions}

1. Why and how does Ella's Kitchen engage with its vision, mission and purpose?

2. What are strengths and limitations of leading with purpose? Where do you see application of purpose-driven leadership in your organization or context?

3. How does Ella's Kitchen engage with its values?

4. What are strengths and limitations of leadership that builds on culture and values? How does your organization or context compare to the way the case shows values-based leadership? 
5. How does energy manifest at Ella's Kitchen? What is the expected impact for the organization?

6. What is the role of leadership in energizing people in organizations? What is the role of leadership in sustaining shared energy in organizations?

7. How can you describe the energy states in your organization or context? What leadership lessons can you draw for this energy state based on your learning from the case study?

\section{References}

Albrecht, S. L. (2013). Work engagement and the positive power of meaningful work. In A. B. Bakker (Ed.), Advances in positive organizational psychology (Vol. 1, pp. 237-260). Bingley, England: Emerald.

Barrick, M. R., Thurgood, G. R., Smith, T. A., \& Courtright, S. H. (2015). Collective organizational engagement: Linking motivational antecedents, strategic implementation, and firm performance. Academy of Management Journal, 58(1), 111-135. doi: 10.5465/amj.2013.0227

Barsade, S. G. (2002). The ripple effect: emotional contagion and its influence on group behavior. Administrative Science Quarterly, 47(4), 644-675. doi: 10.2307/3094912

Baumeister, R. F., \& Leary, M. R. (1995). The need to belong: Desire for interpersonal attachments as a fundamental human motivation. Psychological Bulletin, 117(3), 497-529. doi: 10.1037/00332909.117.3.497

Baumeister, R. F. \& Vohs, K. D. (2002). The pursuit of meaningfulness in life. In C. R. Snyder \& S. J. Lopez (Eds.), Handbook of positive psychology (pp. 608-618). New York, NY, US: Oxford University Press.

Boal, K. B., \& Hooijberg, R. (2000). Strategic leadership research: moving on. The Leadership Quarterly, 11(4), 515-549. doi: 10.1016/S1048-9843(00)00057-6

Bono, J. E., \& Ilies, R. (2006). Charisma, positive emotions and mood contagion. The Leadership Quarterly, 17(4), 317-334. doi: 10.1016/j.leaqua.2006.04.008

Bruch, H., \& Vogel, B. (2011). Fully charged: How great leaders boost their organization's energy and ignite high performance. Boston, MA: Harvard Business Review Press.

Cameron, K. S. (2008). Positive Leadership: Strategies for Extraordinary Performance. San Francisco, CA: Berrett-Koehler.

Cameron, K. S., Dutton, J. E., \& Quinn, R. E. (Eds.) (2003). Positive organizational scholarship. San Francisco, CA: Berrett-Koehler. 
Cameron, K. S., \& Spreitzer, G. M. (2013). The Oxford Handbook of Positive Organizational Scholarship. New York, NY: Oxford University Press.

Carmeli, A., Dutton, J. E., \& Hardin, A. E. (2015). Respect as an engine for new ideas: Linking respectful engagement, relational information processing and creativity among employees and teams. Human Relations, 68(6), 1021-1047. doi: 10.1177/0018726714550256

Cha, S. E., \& Edmondson, A. C. (2006). When values backfire: Leadership, attribution, and disenchantment in a values-driven organization. The Leadership Quarterly, 17(1), 57-78. doi: 10.1016/j.leaqua.2005.10.006

Cole, M. S., Bruch, H., \& Vogel, B. (2012). Energy at work: A measurement validation and linkage to unit effectiveness. Journal of Organizational Behavior, 33(4), 445-467. doi: 10.1002/job.759

Dutton, J. E. (2003). Energize your workplace: How to create and sustain high-quality connections at work. San Francisco, CA: Jossey-Bass.

Dutton, J. E., \& Spreitzer, G. M. (Eds.). (2014). How to be a positive leader: Small actions, big impact. San Francisco, CA: Berrett-Koehler.

Glynn, M. A., \& Watkis, L. (2010). Symbolism in organizations. The generative potency of cultural symbols: Implications for positive organizational scholarship. In K. Cameron \& G. Spreitzer (Eds.), The Oxford handbook of positive organizational scholarship (pp. 617-628). Oxford, England: Oxford University Press.

Grant, A. (2012). Leading with meaning: Beneficiary contact, prosocial impact, and the performance effects of transformational leadership. Academy of Management Journal, 55(2), 458-476. doi: 10.5465/amj.2010.0588

Grant, A. M. (2007). Relational job design and the motivation to make a prosocial difference. Academy of Management Review, 32(2), 393-417. doi: 10.5465/AMR.2007.24351328

Grint, K. (2005). Leadership: Limits and possibilities. New York, NY: Palgrave Macmillan.

Haertel, C. E. J., \& Ashkanasy, N. M. (2010). Healthy human cultures as positive work environments. In N. M. Ashkanasy, P. M. Wilderom, \& M. F. Peterson, Handbook of organizational culture and climate (pp. 85-100). Thousand Oaks, CA: Sage.

Hackman, J. R., \& Oldham, G. R. (1976). Motivation through the design of work: Test of a theory. Organizational Behavior and Human Performance, 16(2), 250-279. doi: 10.1016/00305073(76)90016-7

Hatfield, E., Cacioppo, J. T., \& Rapson, R. L. (1994). Emotional contagion. Cambridge, England: Cambridge University Press.

Johnson, S. K. (2008). I second that emotion: Effects of emotional contagion and affect at work on leader and follower outcomes. The Leadership Quarterly, 19(1), 1-19. doi:

10.1016/j.leaqua.2007.12.001 
Kempster, S, Jackson, B., \& Conroy, M (2011) Leadership as purpose: Exploring the role of purpose in leadership practice. Leadership, 7 (3), 317-34. doi: 10.1177/1742715011407384

Koonce, R. (2016). All in "the family": Leading and following through individual, relational, and collective mindsets. In R. Koonce, M. Bligh, M. K. Carsten, \& M. Hurwitz (Eds). Followership in action: Cases and commentaries (pp. 3-13). Bingley, England: Emerald.

Kotter, J. P., \& Heskett, J. L. (1992). Corporate culture and performance. New York, NY: Free Press.

Lord, R. G., \& Brown, D. J. (2001). Leadership, values, and subordinate self-concepts. Leadership Quarterly, 12(2), 133-152. doi: 10.1016/S1048-9843(01)00072-8

Menges, J. I., Walter, F., Vogel, B., \& Bruch, H. (2011). Transformational leadership climate: Performance linkages, mechanisms, and boundary conditions at the organizational level. The Leadership Quarterly, 22, 893-909. doi: 10.1016/j.leaqua.2011.07.010

Michaelson, C. (2005). Meaningful motivation for work motivation theory. Academy of Management Review, 30(2), 235-238. doi: 10.5465/AMR.2005.16387881

Owens, B. P., Baker, W. E., McDaniel Sumpter, D., \& Cameron K. S. (2016). Relational energy at work: Implications for job engagement and job performance. Journal of Applied Psychology, 101(1), 35-49. doi:10.1287/orsc.1120.0795

Podolny, J. M., Khurana, R., \& Hill-Popper, M. (2004). Revisiting the meaning of leadership. Research in Organizational Behavior, 26, 1-36. doi: 10.1016/S0191-3085(04)26001-4

Quinn, R. W., \& Dutton, J. E. (2005). Coordination as energy-in-conversation. Academy of Management Review, 30(1), 36-57. doi: 10.5465/AMR.2005.15281422

Quinn, R. W., \& Quinn, R. E. (2015). Lift: The fundamental state of leadership (2nd ed.). Oakland, CA: Berrett-Koehler.

Quinn, R. W., Spreitzer, G. M., \& Lam, C. F. (2012). Building a sustainable model of human energy in organizations: Exploring the critical role of resources. The Academy of Management Annals, 6(1), 337-396. doi: 10.1080/19416520.2012.676762

Rokeach, M. (1973). The nature of human values. New York, NY: Free Press.

Rokeach, M. (2008). Understanding human values. New York, NY: Free Press.

Spreitzer, G. M., \& Sonenshein, S. (2004). Toward the construct definition of positive deviance. American Behavioral Scientist, 47(6) 828-847. doi: 10.1177/0002764203260212

Vogel, B., \& Bruch, H. (2011). Organizational energy. In K. Cameron \& G. Spreitzer (Eds.), The Oxford handbook of positive organizational scholarship (pp. 691-702). New York, NY: Oxford University Press. 
Wrzesniewski, A., Dutton, J. E., \& Debebe, G. (2003). Interpersonal sensemaking and the meaning of work. Research in Organizational Behavior, 25, 93-135. doi: 10.1016/S0191-3085(03)25003-6

Yukl, G. (2008) How leaders influence organizational effectiveness. The Leadership Quarterly, 19, 70822. doi: 10.1016/j.leaqua.2008.09.008

\section{AUTHOR BIOS}

Dr Amal Ahmadi is a Post-doctoral Fellow of Leadership and Organisational Behaviour and Member of the Henley Centre for Engaging Leadership at the Henley Business School, University of Reading. Amal worked in the banking and financial services industry prior to pursuing her academic roles at the Henley Business School. She holds a BA in Economic and Social Studies, specialising in Accounting and Finance from the Manchester Business School, University of Manchester, UK, and both MSc in International Management, and $\mathrm{PhD}$ in Leadership and Organisational Behaviour from the Henley Business School, University of Reading, UK. Amal's research interests include leadership, leadership development, and workplace emotions, drawing on cognitive, affective and behavioral mechanisms to understand the phenomena. She won the Best Doctoral Paper award at the 9th Conference on Emotions and Organizational Life (Emonet IX) in 2014, for a paper that explored the knowing-doing gap in leadership. It focused on the role of leader fear and the leadership context in influencing the transfer of leadership knowledge into leadership action. The paper is published in the $12^{\text {th }}$ volume of Research on Emotion in Organizations.

Her teaching expertise includes the areas of leadership, organisational behaviour, management skills, career consultancy, and entrepreneurship.

Dr Bernd Vogel is the Director of the Henley Centre for Engaging Leadership and an Associate Professor of Leadership and Organizational Behaviour at the Henley Business School, University of Reading. Earlier roles include project leader in the Organizational Energy Program (OEP) and Lecturer at the University of St. Gallen, Switzerland, and Visiting Scholar at the Marshall School of Business, University of Southern California. He received his PhD from the University of Hannover, Germany.

Bernd's research focuses on new forms, sources, and practices of engaging leadership, mobilizing and maintaining energy in organisations and senior management teams, creating leadership and followership capacity, co-creating leadership, CEO decision making and identity, and organizational change.

He has published in international top-tier journals and developed several case studies about leadership in multinational businesses. His latest book is called "Fully Charged: How Great Leaders Boost Their Organization's Energy and Ignite High Performance".

He is teaching, consulting, and speaking internationally for global companies and universities based on his expertise in creating and sustaining organizational energy, developing leadership and followership capability, developing management teams, or leading change. He is also a certified coach. Bernd has worked with global clients from various sectors including retail, FMCG, manufacturing or luxury fashion. 